\title{
El rescate de una fuente histórica: \\ los libros de visita de cárcel \\ (El caso de Quito, 1738-1750)
}

Tamar Herzog

Universidad Hebrea de Jerusalén, Israel

El trabajo describe las visitas de cárcel en general y en la ciudad de Quito en particular, poniendo énfasis sobre su ejecución práctica y sus resultados. Desea atraer la atención de los historiadores sobre los libros de visita, hasta el presente poco estudiados, demostrando su posible contribución a la investigación, tanto social como judicial, del mundo colonial hispanoamericano. Permite conclusiones sobre la división de competencias, la distribución de la actividad administrativa según épocas y estaciones del año, el alcance real de los indultos generales, el incumplimiento de las penas, etc.

\section{La visita de cárcel}

A primera vista, los libros de visita de cárcel son una fuente monótona, solo reducible a un análisis cuantitativo de tipo estadístico. Sus listas de presos y fechas de estancia servían, tradicionalmente, para asegurar la existencia de una cárcel, de un sistema judicial y de una ejecución más o menos fiel de las instrucciones reales sobre las prisiones. Sin embargo, a pesar de la primera impresión, se trata de una fuente de gran riqueza que, entre líneas, cuenta una historia social y administrativa irrecuperable por otros medios. El siguiente artículo se basa en el estudio de los libros de visita de la cárcel de corte de Quito entre 1738 y 1750 y especialmente entre 1738 y 1740 . Quiere atraer la atención sobre una fuente olvidada a pesar de su gran interés y hacer varias afirmaciones sobre la administración de justicia en la América colonial.

La visita de cárcel era una institución hispánica cuyos antecedentes se remontan a las Siete Partidas. ' Mediante su ejecución los jueces vigilaban las actividades del alcaide, la legalidad de los arrestos y la buena administración del sistema judicial. La visita se ejecutaba una vez por

I La Partida 7,XXIX,8 fija, por ejemplo, la obligación del alcaide de dar, mensualmente, a los alcaldes razón de los presos (sus nombres, el tiempo que llevaban en la cárcel y el motivo de la prisión) que se hallaban en las instalaciones penitenciarias. 
semana y se desarrollaba, normalmente, en dos fases; la primera en la sala pública en presencia de los ministros superiores, fiscal, escribanos y procuradores, y la segunda en la misma cárcel con asistencia de algunos oidores escogidos por turno y del alcaide. ' La sesión se iniciaba con la lectura de la lista de presos, la presentación de peticiones de salida y la decisión judicial en todos los casos requeridos. Posteriormente se pasaba a la verdadera "visita", es decir, se entraba a las instalaciones penitenciarias para detectar su estado físico (aseo, provisión de agua potable, etc.) y para entrevistarse con los presos sin la mediación de sus procuradores y averiguar el tratamiento que se les daba.

Como cualquier otra garantía procedimental y administrativa, la visita de cárcel se convirtió en una ceremonia elaborada y pomposa, sin carácter operativo. Abundaban en ella las luchas sobre asientos y precedencias y se exigía un decoro (comportamiento decente) de quien participaba en ella, fuera en calidad de actor, fuera en calidad de espectador. ${ }^{3}$

La legislación regia, insistiendo en la importancia de llevar a cabo puntualmente la visita de cárcel, ${ }^{4}$ intentaba asegurar que su enfoque no pasara del justo amparo que el rey —en calidad de pastor- debía asegurar a sus vasallos. Mientras repetía la obligación de ejecutar la visita, luchaba contra su transformación en un mecanismo que favorecía procedimientos sumarios y abreviados (sin garantías procedimentales) 0 , al contrario, que posibilitaba la salida de presos antes del tiempo previsto y sin conocer a fondo sus causas, demostrando una benevolencia exagerada. 5

2 La visita de cárcel en la Península fue descrita, por ejemplo, en los libros de práctica de los tribunales de Navarra ("Ceremonia y estilo de los tribunales del Reino de Navarra", libro manuscrito atribuido al oidor Jeloaga el viejo [siglo XVIII], Biblioteca Nacional/ Madrid [en adelante BN], Mss. 9901, en págs. 101-106) y de Granada ("Práctica de la Chancillería de Granada XVIIXVIII", anónimo, sigto XVIII, BN, Mss. 309, págs. 530 y sigs.) y en una cédula real de 4 de septiembre de 1576 en lo tocante a Valladolid (Archivo Histórico Nacional/ Madrid [en adelante AHN], Códices, 721B, núm. 29, págs. 32-34). La visita de cárcel fue analizada desde una perspectiva positivista por E. Martiré: "La visita de cárcel en Buenos Aires durante el virreinato", XVIII Congreso del Instituto Internacional de Historia del Derecho Indiano, Revista Chilena de historia del derecho, núm. 13, 1987, págs. 39-60; Bernal Gơmez, B.: "Un aspecto más del régimen carcelario novohispano: la visita de cárcel", en: Poder y presión fiscal en la América española (siglos XVI, XVII, XVIII): VI Congreso Internacional del Instituto de Historia del Derecho Indiano, Valladolid, 1986, págs. 255-279, y Lozano Armendras, T.: La criminalidad en la ciudad de México 1800-1821. México, 1987, págs. 167-168.

3 AHN, Códices, 723B, núm. 106, págs. 90-91 cédula de 1632.

4 AHN, Códices, 7IIB, núm. 205, pág. 359 y núm. 207, pág. 360.

5 BN, Mss. 2989, fols. 1108-1109 y Biblioteca del Palacio Real en Madrid (en adelante BPR), Mss. 2847, fols. 337-357. 


\section{La visita de cárcel en Quito}

La visita de cárcel se ejecutaba en Quito a imitación de los tribunales peninsulares. ${ }^{6}$ Las ordenanzas de la Audiencia de 1563 recogían la obligación de practicarla todos los sábados con asistencia de dos a tres jueces, un alguacil y un escribano. ${ }^{7}$ Los documentos administrativos y judiciales consultados muestran que en Quito la visita se hacía en la sala pública de la Audiencia después de acabar el despacho ordinario y en presencia de todo el personal. Los escribanos leían la memoria de los reos, los procuradores pedían por sus clientes y los oidores decretaban. A menudo - fuera por decisión propia del tribunal, fuera por petición expresa de la parte interesada - el reo presenciaba la sesión y los oidores escuchaban sus alegaciones o simplemente se dejaban impresionar por su aspecto físico. ${ }^{8} \mathrm{Al}$ acabar la primera fase de la visita, los jueces de turno bajaban a inspeccionar las instalaciones carcelarias.

La visita de cárcel parecía servir, ante todo, para calmar la conciencia de los jueces y de la administración, ya que sólo en muy raras ocasiones se utilizaba para corregir errores y reprimir abusos por parte de jueces inferiores y del personal subalterno del sistema, alcaides incluidos. En Quito, por ejemplo, los oidores solían decretar "sigue y use de su derecho", es decir, que cada reo hiciera lo que le pareciera y lo que pudiera según la ley, negándose ellos a intervenir en su prisión o en su proceso. ${ }^{9}$ Por lo general, los jueces estaban dispuestos a dar órdenes operativas y favorables a los encarcelados sólo cuando éstas obedecían a un interés ulterior; la práctica más común era, por ejemplo, indultar a reos dispuestos a ir de soldados a zonas conflictivas donde faltaban fuer-

6 La relación entre la práctica peninsular y americana se constituyó por ley y de forma expresa. A la Audiencia de Lima, por ejemplo, se le ordenó seguir el procedimiento practicado en Valladolid en lo tocante a la visita de cárcel (AHN, Códices, 72IB, núm. 29, págs. 32-34). Este tema fue mencionado, igualmente, por Bernal Gómez, B.: “Un aspecto más...”, págs. 255-266.

7 Ordenanzas de la Real Audiencia de Quito (publicadas por el V Congreso del Instituto Internacional de Historia del Derecho Indiano, Quito- Guayaquil, 1978), núm. 24. Esta obligación fue nuevamente mencionada por el acuerdo de 26 de septiembre de 1665 (Autos acordados de la Real Audiencia de Quito 1578-1722: Anuario histórico jurídico ecuatoriano, v. 2, 1971, pág. 109).

8 Véase la descripción del inicio de la visita en Archivo Histórico/ Quito (en adelante AHQ), Oficios, 22: Expediente 16 de septiembre de 1724 y Archivo General de Indias/ Sevilla (en adelante AGI), Quito, 162: certificado del escribano Alonso Sánchez Maldonado de 14 de agosto de 1704.

9 AHQ, Criminales, 14: expediente 24 de mayo de 1695 y AHQ, Criminales, 32: expediente 7 de junio de 1743. Lo mismo se deduce de los libros de visita de cárcel cuya cita está a continuación. 
zas. ${ }^{10}$ Otro decreto bastante frecuente en las visitas de cárcel era la declaración de "pobre de solemnidad". "Sólo en muy pocas ocasiones la ceremonia semanal de visita servía para su destino oficial, es decir, para soltar presos cuyo encarcelamiento no estaba justificado por las reglas del derecho, ${ }^{12}$ someter su causa a un juez ${ }^{13}$ o llevar a cabo cualquier otro trámite de procedimiento necesario. ${ }^{14}$

A pesar de la aparente ineficiencia de la institución, los libros de visita de cárcel hallados en Quito ${ }^{15}$ dan testimonio de su existencia continua, al menos en lo tocante a la cárcel de corte y entre 1646-1649 y 1738-1759. Según éstos, las visitas se llevaban a cabo cada 5 a 14 días y en ellas participaba la Audiencia entera. Como ya hemos mencionado, las visitas cobraban un aspecto ceremonial, centrado, al parecer, en su propia repetición y supuesta perpetuidad que se constituían, a su vez, en garantías cuya mera existencia contaba más que su contenido.

Los jueces y el personal subalterno - acostumbrado a que las visitas no produjesen censuras contra sus decisiones ni actuaciones- se sentían ofendidos cuando los ministros que las ejecutaban se salían de la regla general e intervenían en la prisión de ciertos reos o en el desarrollo de sus causas. De esta manera, por ejemplo, el oidor Juan Larrea explicó en 1692 el odio que le tenía el corregidor Manuel Torre y Angulo, ${ }^{16}$ y contó que al hacer la visita de cárcel halló en ella un mozo español, preso por el corregidor por una causa muy leve, que sin información judicial fue azotado por orden suya 400 veces. Larrea reprendió al corregidor públicamente, insistiendo que las cárceles "no eran para semejantes castigos" por tener un carácter preventivo, y explicando que las penas se daban sólo al final de un proceso judicial y en virtud de una sentencia.

10 AHQ, Criminales.4: expediente 30 de marzo de 1662; AHQ, Criminales, 6: expediente 19 de diciembre de 1676 y AHQ, 4a Notaria, 26: expediente 10 de noviembre de 1742.

II La declaración de "pobre de solemnidad" otorgaba a los reos el derecho a obtener servicios gratuitos de procurador y abogado y les liberaba de los costos del proceso. AHQ, Criminales, 12: expediente 16 de noviembre de 1691.

12 Véase lo ocurrido en AHQ. Criminales, 14: expediente 23 de febrero de 1696 y AHQ. Criminales, 12: expediente 16 de noviembre de 1691.

13 AHQ. Criminales, 14: expediente 16 de enero de 1696 y AHQ. Criminales, 16: expediente 12 de agosto de 1704 .

14 Los trámites procedimentales incluían, por ejemplo, el dar una orden administrativa de azotar un reo, castigando su fuga de la prisión, decidir tomar su confesión, etc. AHQ, Criminales, 27: expediente 12 de diciembre de 1732 y AHQ. Criminales, 14: expediente 11 de enero de 1697. respectivamente.

15 Véase a continuación.

16 AGI, Quito, 72, fols. 119-221. 


\section{Los libros de visita de cárcel: Quito 1738-1750}

Las visitas de cárcel han dejado huellas en decenas de documentos administrativos y en centenares de pleitos civiles y causas penales, sin embargo, su testimonio más coherente, sistemático y abundante se halla en los libros de visita de cárcel. En Quito responden a ésta categoría un libro del siglo XVII y dos libros del siglo posterior, ${ }^{17}$ todos pertenecientes a las sección de "Prisiones" del Archivo Nacional.

Los libros de visita de Quito se caracterizan por la brevedad de la información; incluyen la fecha, nombres de los reos y las decisiones del juez, normalmente mediante una sola palabra o una sola frase. Repiten, continuamente, que "el presidente y los oidores hicieron visita a la cárcel en la manera siguiente (nombres de personas, causa y decisión en una lista)... con lo que acabó dicha visita y los dichos señores lo rubricaron...". Sin embargo, y a pesar de su parecer monótono y de poco contenido, las actas son una fuente rica y normalmente olvidada para el estudio de la administración de justicia en la sociedad colonial. Los siguientes son unos ejemplos del análisis que son capaces de provocar y sostener.

\section{a) La existencia de una actividad estacional}

Los libros de visita de cárcel ponen de relieve que la administración de justicia penal, al menos en sus niveles iniciales de encarcelamiento, funcionaba según estaciones y temporadas. Desde un punto de vista climático, por ejemplo, los meses de mayor actividad solían ser, en general, los del verano (la época seca) y los próximos a ellos. Al contrario, los meses de enero, febrero, marzo y abril (la época de mayor lluvia) eran de una actividad más reducida. Aunque es imposible decir si el clima espantaba a los criminales - que reducían sus actividades-o a los jueces - que no querían perseguirlos- es posible afirmar, de todas formas, que la época lluviosa correspondía a tiempos de relativa paz para la administración de justicia.

17 AHQ, Prisiones, 1: expediente sin fecha titulado "visitas de cárcel 1646-1649" (cubre la época entre 10 de marzo de 1646 y 3 de abril de 1649) y AHQ. Prisiones, 2: expedientes 24 de octubre de 1738 (cubre la época 6 de septiembre de 1738-2 de mayo de 1749) y 27 de septiembre de 1749 (cubre la época 13 de septiembre de 1749-26 de mayo de 1759). 
La relación entre temporada y actividad existía, igualmente, en lo tocante a la aparición y desaparición de ciertas actividades delictivas. Mientras que en algunas visitas la cárcel se hallaba llena de "jugadores", "personas cogidas por la ronda" o "tributarios", en otras ocasiones no había ni un solo representante de estos sectores. De forma parecida, desde la primavera de 1741 y hasta finales de julio de aquel año abundaron de una forma inusual las causas por problemas intra-familiares ("echar manos al padre", amistades ilícitas, no hacer vida matrimonial, etc.), poco frecuentes en otras épocas. En los meses de diciembre, enero y febrero de todos los años se notaba una gran actividad de los oficiales reales quienes encarcelaban a deudores de la Real Hacienda en la ocasión de tener que cerrar los libros y cuentas del año acabado y preparar los del año entrante. ${ }^{18}$

La relación entre temporada y tipo de crimen perseguido se debía, al parecer, al despertar de los jueces y no a una variación importante en la actividad social y delictiva en la ciudad. Las "campañas de limpieza" así ejecutadas acababan, normalmente, con un breve encarcelamiento de los reos o deudores, haciendo demostración del celo y dedicación de los jueces más que resolviendo problemas realmente existentes. ${ }^{19}$

La dependencia entre encarcelamiento y celo -individual o colectivo- de los jueces tenía otra expresión en la existencia de magistrados muy activos y otros que, al contrario, casi nunca aparecían en las actas en calidad de iniciadores de procesos. El oidor que más prisiones decretaba era José Quintana y Acevedo, cuyos presos monopolizaron a menudo la cárcel de corte. Respondiendo a una línea general de evolución de la actividad judicial en Quito, o, tal vez, creándola él mismo, Quintana y Acevedo fue especialmente activo entre 1742 y 1744 . Aunque siguió siendo el oidor más laborioso hasta 1750, a partir de 1744 su actividad se redujo a la mitad e incluso a un tercio. Fuera por afición propia, fuera por necesidad "objetiva", Quintana y Acevedo persiguió especialmente a los que él mismo clasificó de ladrones, incluyendo en el término, al parecer, receptores y compradores de mercancías y bienes hurtados. Otro oidor relativamente activo, aunque en menor grado que Quintana y Acevedo, era Manuel Rubio de Arévalo, especialmente presente en las actas

\footnotetext{
18 Véase lo ocurrido en febrero de 1739 y enero de 1740.

19 Este era el caso en la mayoría de las ofensas tratadas por temporadas. La única excepción a ésta regla son, a veces, las prisiones hechas por los oficiales reales, tratadas a continuación.
} 
de 1739 y 1740, es decir, antes de su designación como visitador del presidente José Araujo y Río y su conversión -en calidad de juez de visita - en presidente interino de la Audiencia. Las actividades de Pedro Gómez de Andrade, otro oidor quiteño, cobraron una especial importancia durante algunos meses de 1748.

Los libros de visita permiten incluso reconstruir los días en los que se ejecutaba la ronda nocturna y estimar su eficacia. Las actas del 26 de septiembre de 1739 denotan, por ejemplo, el turno del oidor José Llorente quien, durante la ronda, encarceló tres personas. En noviembre de 1739 Manuel Rubio de Arévalo buscó especialmente a los "ladrones" y ejecutó muchas prisiones en calidad de rondador.

\section{b) Las diferencias jurisdiccionales}

Los libros de visita ponen de manifiesto la existencia de una distinción clara y formalmente declarada entre la Audiencia como un cuerpo colegial y sus ministros como jueces individuales. Las listas clasificaron los presos según fueran de la Audiencia, del Juzgado de provincia ${ }^{20}$ o de un oidor particular. Aparte de anotar este hecho diferencial a continuación del nombre de cada reo, las actas demuestran que los ministros, concurridos a la visita en cuerpo colegial ("La Audiencia"), se sentían con derecho a intervenir - salvo en casos de ilegalidad - sólo en las actuaciones hechas por el tribunal entero. Cuando se trataba de causas y pleitos bajo la tutela de los miembros individuales de la Audiencia (oidores) o del Juzgado de provincia (igualmente personificado en un oidor individual), el tribunal como cuerpo colegial se mostraba contrario a averiguar el caso, tratándolo como si fuera un asunto perteneciente a un cuerpo ajeno. La existencia física del oidor - juez del caso- in situ no cambiaba nada; al ser la visita un acto celebrado por el tribunal como institución, cada ministro perdía en ella su carácter de persona particular y se convertía en un miembro anónimo de un colectivo, no pudiendo obrar en virtud y nombre propios. Con esta conformidad, mientras que se ordenaba "siga" en lo que tocaba a los reos de la Audiencia (es decir, se decidía seguir con el estado presente de las cosas), se decretaba

20 El Juzgado de provincia pertenecía a la Audiencia. Los oidores se sentaban en él por turnos y se dedicaba a ver pleitos civiles de primera instancia procedentes de la jurisdicción de la ciudad de Quito (ciudad y cinco leguas). 
"ocurra" (al magistrado competente) en los demás casos (causas vistas por oidores particulares y por el juez de provincia). Para toda la época desde 1748 hasta 1750 no se conoce ni un solo caso en el que la visita produjese un auto diferente, que engendrase una intervención de la Audiencia en asuntos no considerados suyos.

\section{c) Los indultos ordinarios y extraordinarios}

Los libros de visita de cárcel ponen en evidencia, además, la futilidad, a nivel local y dentro de las instalaciones de corte, de los indultos de Pascua de Navidad y de Resurrección. ${ }^{21}$ Aunque muchos reos respondían a los términos de la gracia — anunciada y recogida en los librostodos ellos seguían en prisión. A pesar de ello, el rito de anunciar el indulto - rito fijado por la ley y la tradición - siguió durante toda la época estudiada, dando igual, al parecer, su alcance práctico mínimo, incluso inexistente.

Los indultos extraordinarios, relacionados con festejos en la corte peninsular (especialmente nacimientos y coronaciones) sufrían de una suerte similar. En 1747, por ejemplo, Fernando VI, recién coronado, decretó un indulto general cuyos términos eran muy parecidos a los incluidos en las gracias regulares de las Pascuas. A los pocos días de su publicación en Quito, se insertó en los libros de visita una lista de reos que por sus circunstancias personales y por su ofensa calificaban a sus condiciones. Se trataba de tres personas, dos de ellas clasificadas de "ladrones" y una de "haber hecho dos muertes". A pesar del indulto, sólo uno de los tres ("ladrón") consiguió salir de la prisión, quedando los otros dos en la cárcel. Tras dos semanas en las que se les siguió llamando "indultados", su status volvió al de siempre: eran reos y nada indicaba, a continuación, que hubieran sido indultados $\mathrm{y}$, en la práctica, nunca gozaron del privilegio.

\section{d) El desarrollo de la criminalidad}

Los libros de visita anotan una intensificación en la actividad carcelaria de 1739 hasta 1745 . Al contrario, a partir de 1745 y hasta 1750 se registró en ellos un lento descenso de la misma. Por otro lado, la pre-

21 Se trataba de indultos fijados por ley, en los que se perdonaba, normalmente, a reos de casos criminales y se soltaba, automáticamente, a los deudores que no debían dinero a la Real Hacienda sino a personas particulares. 
sencia de reos ladrones y de otros presos encarcelados para una "averiguación de robo" se incrementó continuamente hasta 1750, e incluso llegó a dominar las cárceles a partir de 1749. ${ }^{22}$

Con el transcurso del tiempo la tendencia a detallar las razones por las que los reos ingresaban en prisión aumentó. Mientras que en la década de 1730 se apuntaba sólo el nombre de la persona y de la autoridad que decretó su encarcelamiento, poco a poco se pasó a un sistema que describía la acusación contra cada preso, primero en términos genéricos ("robo", "muerte", "ronda") y posteriormente con un mayor detalle (robo de qué, de quién, dónde, etc.). Paralelamente, la insistencia sobre la identidad de la persona que decretó la prisión, es decir, sobre su legalidad y sobre el trabajo continuo de los jueces, dio paso a un nuevo sistema que precisó, más bien, los contenidos de la actividad judicial: cuál era el problema a resolver y qué se hacía con el.

\section{e) El encarcelamiento: análisis cuantitativo (1738-1740) ${ }^{23}$}

Entre septiembre de 1738 y el mismo mes de 1740, 120 personas ingresaron en la cárcel de corte de Quito, de las que 54 estuvieron presentes en una sola visita, es decir, estuvieron en prisión al menos un día (el día de la visita) y por una duración máxima de 14 días. ${ }^{24}$ Otros 100 reos pasaron en la prisión menos de 100 días, (en promedio, 27.6 días). Los 20 reos restantes (16\% aproximadamente) estuvieron en la cárcel por un período más largo. ${ }^{25}$ Las dos personas que más tiempo pasaron en prisión (503 y 543 días) eran deudores de la Real Hacienda, encarcelados por los oficiales reales. Los otros reos que sufrieron estancias largas en la cárcel pertenecían a la misma categoría, eran "ladrones" o, en la mitad de los casos, los libros de visita no especificaban su causa de prisión.

22 Véase la visita de 31 de mayo de 1749.

23. Este análisis se basa en el estudio de las personas ingresadas en la cárcel de corte de Quito entre 27 de septiembre de 1738 y 24 de septiembre de 1738.

24 El cálculo de 14 días se basa en la posibilidad de que entraron en la cárcel en un día de visita, pero después de su ejecución, y que fueran liberados de ella en un día de visita, pero antes de su ejecución y que entre las dos fechas estuvieron presentes en una visita.

25 Las cifras exactas son: 10 reos $(8 \%)$ se quedaron en ella entre 100 y 200 días, $5(4 \%)$ entre 200 y $300,3(2.4 \%)$ entre 300 y 400 y $2(1.06 \%)$ entre 500 y 550 . Estas cifras elevan el promedio de estancia en la cárcel a 74.8 días (cálculo que incluye a los 120 reos cuyos casos fueron estudiados). 
Los jueces que más reos pusieron en prisión eran los oidores. Para la época que nos interesa (1738-1740) 24 personas entraron en ella por orden de Manuel Rubio de Arévalo, 17 por la de Pedro Gómez de Andrade, 16 por la de José Llorente y uno por la de Esteban Olaís. Los siguieron los oficiales reales, con 21 encarcelados. Luego venía la Audiencia con 15 y el presidente y el juez de provincia, con 13 cada uno de ellos. ${ }^{26}$ En los dos años estudiados hubo sólo 4 casos de reos reincidentes. ${ }^{27}$

\section{f) La ejecución de las penas}

Otro fenómeno que los libros de visita destacan es la abundancia de presos convictos cuya sentencia, dada y revista, no se ejecutaba durante muchos días e incluso semanas y meses. La pasividad de los jueces frente a estos casos es absoluta: comunican a los reos su derecho a exigir la ejecución, pero no insisten en ello, ni toman la iniciativa para garantizarlo. En la mayoría de estos casos, los reos seguían en prisión visita tras visita, a veces durante meses, sin que el sistema hiciese nada para regular su situación. ${ }^{28}$

\section{Conclusión}

Los libros de visita de cárcel reflejan una administración de justicia lenta y pasiva, donde importaba más la ceremonia y el respeto a las jurisdicciones y a la persona del juez que la eficacia y el control sobre las actividades de los miembros individuales del sistema. Se trataba de una estructura que repetía fielmente las visitas a las instalaciones penitenciarias a pesar de su eficacia mínima, tal vez inexistente, si no fuera por su

26 Los demás reos fueron encarcelados por una entidad no especificada (4 casos), por el alguacil mayor de corte ( 3 casos), por el juez de bienes de difuntos ( 2 casos) y por el Santo Oficio ( 1 caso).

27 Se trataba de Vincente Albán (reo por deuda entre 22 de enero de 1740 y 13 de febrero de 1740 y nuevamente por el juez de provincia - posiblemente por deuda - entre 25 de junio de 1740 y 15 de julio de 1740), del procurador de número Antonio Muela (reo a finales de 1738 y en 1740, una vez por los oficiales reales y tres veces por la Audiencia), de Manuel Sosa (encarcelado por el juez de provincia en 27 de junio de 1739 y nuevamente entre 24 de octubre de 1739 y 7 de noviembre de 1739) y de Agustín Suárez (encarcelado por el oidor Llorente desde 7 de mayo de 1740 y hasta 28 de mayo de 1740 y nuevamente desde 9 de julio de 1740 y 23 de julio de 1740).

28 Véase, por ejemplo, pág. 41 del expediente 20 de octubre de 1738, antes citado. 
aspecto hipotéticamente persuasivo. Los reos quedaban en prisión incluso al ser indultados y la existencia de una sentencia no garantizaba, necesariamente, su ejecución. Además, como cualquier otro sistema bionatural, la administración de justicia parecía seguir las pautas estacionales - aumentando su actividad en los meses de verano- y temporales -la persecución de ciertos delitos según épocas y el celo individual de cada juez-.

Los libros de visita de cárcel confirman algunas opiniones tradicionalmente tenidas y aportan nuevas ideas sobre la Justicia americana en la época colonial. Permiten investigar no sólo a los supuestos delincuentes sino incluso, prioritariamente, el sistema que les clasificaba y les trataba como tales. Su valor para la investigación histórico-administrativa es grande, ya que nos permiten seguir las actuaciones pequeñas, casi cotidianas y de carácter insignificante, tanto de las personas como del aparato de poder, lo que constituía, al fin y al cabo, parte esencial de la clave del gobierno español en las Indias. 